\title{
ANALISIS BANJIR DENGAN STANDARD STEP METHOD DAN PEMETAAN BANJIR DI KELURAHAN JOYOTAKAN, KOTA SURAKARTA
}

\author{
Dewanti Anggit Setia Aji), Rintis Hadiani2), dan Endah Sitaresmi Suryandari3) \\ 1) Mahasiswa Fakultas Teknik, Prodi Teknik Sipil, Universitas Sebelas Maret \\ 2) Pengajar Fakultas Teknik, Prodi Teknik Sipil, Universitas Sebelas Maret \\ 3) Kepala Dinas Pekerjaan Umum Kota Surakarta \\ Jl. Ir. Sutami 36A, Surakarta 57126; Telp.0271-634524. Email: dewantianggit@gmail.com
}

\begin{abstract}
Flooding is water that is abundant from rivers or channels because the capacity is not able to accomodate the water. Joyotakan is one of 26 district in Surakarta that are included in flood areas. The main cause is due to backwater from the meeting point of Premulung River and Kali Wingko. Therefore, research is become a reference in making decisions for flood mitigation.

The floods analyzed is a flood with return periods based on Q2, Q5, Q10, Q20, Q25 and Q50 and The maximum 3-days from the results of the Limantara Hydrograph Synthesis Unit. The flood analysis used is the Standard Step Method, and flood potential mapped using Geographic Information System (GIS).

The results of flood analysis type model I with the sluice gate closed and the pump not active at Q2 is $32.44281 \mathrm{~m} 3 / \mathrm{s}$, and potential maximum depth is $2.6641 \mathrm{~m}$. The retum period of $Q^{5}$ is $34.4001 \mathrm{m3} / \mathrm{s}$, and potential maximum depth is $2.6592 \mathrm{~m}$. The return period of Q10 is $35.7058 \mathrm{~m} 3$ / s, and potential maximum depth is $2.6715 \mathrm{~m}$. The return period of Q20 is 36.9583 $\mathrm{m} 3 / \mathrm{s}$, and potential maximum depth is $2.6838 \mathrm{~m}$. The retum period of $Q 25$ is $36.9583 \mathrm{m3} / \mathrm{s}$, and potential maximum depth is $2.6878 \mathrm{~m}$. The return period of Q50 is $38.5794 \mathrm{m3} / \mathrm{s}$, and potential maximum depth is 2,7003 $\mathrm{m}$. The maximum 3-days is $62.4224 \mathrm{m3} / \mathrm{s}$, and potential maximum depth is 3,0243 m. The results of flood analysis type model II with the shice gate in maximum open condition and the active pump on the return period of 25 is $34.4001 \mathrm{m3} / \mathrm{s}$, and potential maximum depth is $5.2492 \mathrm{~m}$. The return period of Q10 is $35.7058 \mathrm{m3} / \mathrm{s}$, and potential maximum depth is $5.7415 \mathrm{~m}$. The return period of $Q 25$ is $36,9583 \mathrm{m3} / \mathrm{s}$, and potential maximum depth is $8,2078 \mathrm{~m}$. The return period of Q50 is $38.5794 \mathrm{m3} / \mathrm{s}$, and potential maximum depth is $8,4303 \mathrm{~m}$.
\end{abstract}

Keyword: Geographic Information System, Joyotakan, Limantara Hydrograph Synthesis Unit, Standar Step Method.

\begin{abstract}
Abstrak
Banjir adalah air yang melimpah dari sungai atau saluran karena melebihi kapasitas dari tampungan. Kelurahan Joyotakan merupakan salah satu dari 26 wilayah di Surakarta yang masuk dalam daerah rawan banjir. Penyebab utamanya adalah karena terjadi backwater dari pertemuan Sungai Premulung dan Kali Wingko. Oleh karena itu diperlukan penelitian agar dapat menjadi acuan dalam mengambil keputusan untuk penanggulangan banjir.

Banjir yang dianalisis merupakan banjir periode ulang berdasarkan $\mathrm{Q}_{2}, \mathrm{Q}_{5}, \mathrm{Q}_{10}, \mathrm{Q}_{20}, \mathrm{Q}_{25}$ dan $\mathrm{Q}_{50}$ dan $\mathrm{Q}_{3}$ harian dari hasil Hidrograf Satuan Sintesis Limantara. Analisis banjir yang digunakan adalah Standard Step Method, yang kemudian dipetakan dalam peta potensi banjir menggunakan Sistem Informasi Geografis (SIG).

Hasil analisis banjir permodelan I dengan Pintu Air Plalan tertutup dan pompa tidak aktif pada periode ulang $\mathrm{Q}_{2}$ adalah 32,4281 $\mathrm{m}^{3} /$ detik, memiliki elevasi banjir maksimum 2,6641 m. Debit periode ulang Q5 adalah 34,4001 $\mathrm{m}^{3} /$ detik, memiliki elevasi banjir maksimum 2,6592 $\mathrm{m}$. Debit periode ulang $\mathrm{Q}_{10}$ adalah $35,7058 \mathrm{~m}^{3} /$ detik, memiliki elevasi banjir maksimum 2,6715 $\mathrm{m}$. Debit periode ulang $\mathrm{Q}_{20}$ adalah 36,9583 $\mathrm{m}^{3} /$ detik, memiliki elevasi banjir maksimum 2,6838 m. Debit periode ulang $\mathrm{Q}_{25}$ adalah $36,9583 \mathrm{~m}^{3} /$ detik, memiliki elevasi banjir maksimum 2,6878 m. Debit periode ulang $\mathrm{Q}_{50}$ adalah 38,5794 $\mathrm{m}^{3} /$ detik, memiliki elevasi banjir maksimum 2,7003 m. Debit periode ulang Q 3 Harian adalah 62,4224 $\mathrm{m}^{3} /$ detik, memiliki elevasi banjir maksimum 3,0243 m. Hasil analisis banjir permodelan II dengan Pintu Air Plalan terbuka maksimum dan pompa aktif pada periode ulang $Q_{5}$ adalah 34,4001 $\mathrm{m}^{3} /$ detik, memiliki elevasi banjir maksimum 5,2492 $\mathrm{m}$. Debit periode ulang $\mathrm{Q}_{10}$ adalah $35,7058 \mathrm{~m}^{3} /$ detik, memiliki elevasi banjir maksimum 5,7415 $\mathrm{m}$. Debit periode ulang $\mathrm{Q}_{25}$ adalah 36,9583 $\mathrm{m}^{3} /$ detik, memiliki elevasi banjir maksimum 8,2078 m. Debit periode ulang $\mathrm{Q}_{50}$ adalah $38,5794 \mathrm{~m}^{3} /$ detik, memiliki elevasi banjir maksimum 8,4303 m.
\end{abstract}

Kata kunci : HSS Limantara, Kelurahan Joyotakan, Standar Step Method, Sistem Infomasi Geografis.

PENDAHULUAN 
Solo merupakan kota yang berada di Jawa Tengah, memiliki 51 kelurahan. 26 dari 51 kelurahan di Kota Surakarta masuk dalam kategori daerah rawan banjir. Dari pemetaan yang dilakukan Badan Penanggulangan Bencana Daerah (BPBD) Kota Surakarta, ke-26 kelurahan tersebut memiliki wilayah yang menjadi daerah aliran sungai (DAS) yang mengalir di Surakarta. Salah satu kelurahan yang masuk dalam daerah rawan banjir adalah Kelurahan Joyotakan, Kecamatan Serengan (Solopos.com: BPBD Solo, 2017).

Kelurahan Joyotakan masuk dalam daerah tangkapan DAS Kali Wingko. Terdapat pintu air, yang merupakan titik pertemuan antara Sungai Wingko dan Sungai Premulung. Dua sungai tersebut bermuara ke Bengawan Solo. Karena air di Sungai Premulung memiliki elevasi yang lebih tinggi dari elevasi air di Kali Wingko, sehingga terjadi backwater Kali Wingko dan menggenangi kelurahan Joyotakan.

Banjir adalah aliran yang relatif tinggi, dan tidak tertampung oleh alur sungai atau saluran. Aliran yang dimaksud disini adalah aliran air yang sumbernya dari mana saja. Dan air melimpah dari sungai atau saluran karena sungai atau saluran sudah melebihi kapasitas. Kondisi inilah yang disebut banjir (Suparta, 2004).

Penelitian ini dilakukan untuk memperhitungkan besar banjir yang terjadi pada daerah Kelurahan Joyotakan melalui metode analisis banjir. Analisis banjir merupakan prosedur untuk memprediksi banjir yang terjadi. Analisis banjir banyak dilakukan dalam studi pengendalian banjir di sepanjang sungai atau waduk.

Pada penelitian ini metode analisis banjir yang digunakan adalah Standard Step Method, alasan digunakan metode ini adalah dilihat dari permasalahan banjir yaitu akibat backwater. Menggunakan hidrograf satuan sintesis Limantara untuk menghitung debit periode ulang $\mathrm{Q}_{2}, \mathrm{Q}_{5}, \mathrm{Q}_{10}, \mathrm{Q}_{20}, \mathrm{Q}_{25}$ dan $\mathrm{Q}_{50}$ tahun.

Pemetaan genangan banjir Kelurahan Joyotakan menggunakan software ArcGIS, sehingga pada periode waktu tertentu dapat diperbaharui.

\section{LANDASAN TEORI}

Banjir merupakan salah satu bencana alam yang sering terjadi di sekitar kita, terutama di daerah perkotaan yang padat penduduk. Banjir dapat diakibatkan oleh intensitas curah hujan yang terlalu tinggi serta dari kerusakan atau bahkan penyalahgunaan lahan hijau di lingkungan. Oleh sebab itu dibutuhkan adanya penerapan penelusuran banjir (flood routing) yang merupakan analisis hidrologi dalam pencegahan/pengendalian terjadinya banjir (Virdya Nurlaily Andromeda, 2016).

Peralatan yang digunakan untuk mengolah data dalam penelitian ini adalah ArGIS untuk mengetahui data fisik dan pemetaan topografi DAS Bengawan Solo titik tinjauan, Microsoft Excel untuk perhitungan analisis data dan Microsoft Word untuk membuat laporan.

\section{Kepanggahan Data}

Uji konsistensi dilakukan untuk mengetahui apakah data layak digunakan atau tidak. Uji konsistensi yang digunakan dalam penelitian ini adalah metode kurva massa ganda (double mass curve), yaitu dengan membandingkan akumulatif satu stasiun hujan dengan akumulatif rata-rata dari semua stasiun yang digunakan. Model regresi dikatakan sempurna apabila $r^{2}=1$.

\section{Hujan Wilayah}

Data hujan yang diperoleh dari satu stasiun hujan tertentu merupakan hujan yang terjadi hanya pada satu titik saja (point rainfall), maka dari itu hujan titik tersebut harus diubah menjadi hujan wilayah. Hujan wilayah merupakan hujan titik dari beberapa stasiun hujan ynag diolah dan dianggap mewakili hujan yang terjadi di suatu DAS. Pada penelitian ini metode yang digunakan adalah metode poligon thiessen.

Perhitungan hujan wilayah dengan metode Poligon Thiessen dapat menggunakan Persamaan 1 berikut.

$\bar{p}=\frac{A_{1} p_{1}+A_{2} p_{2}+\cdots+A_{n} p_{n}}{A_{1}+A_{2}+\cdots+A_{n}}$

dengan:

$\mathrm{p} \quad=$ hujan rerata kawasan $(\mathrm{mm})$,

$\mathrm{p}_{1}, \mathrm{p}_{2}, \ldots \mathrm{p}_{\mathrm{n}} \quad=$ hujan di stasiun $1,2,3, \ldots . \mathrm{n}(\mathrm{mm})$, dan

$\mathrm{A}_{1}, \mathrm{~A}_{2}, \ldots \mathrm{A}_{\mathrm{n}} \quad=$ luas daerah yang mewakili stasiun $1,2, \ldots \mathrm{n}\left(\mathrm{m}^{2}\right)$.

\section{Distribusi Sebaran}

Distribus Gumbel banyak digunakan untuk analisis data maksimum, seperti untuk analisis frekuensi banjir (Bambang Triatmodjo, 2008). dapat dilihat pada Persamaan 2. 


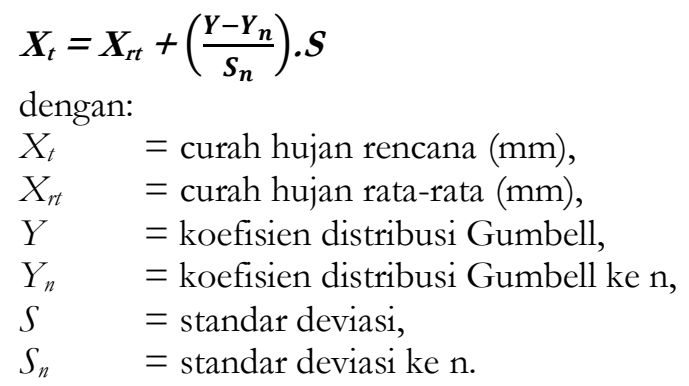

\section{Kecocokan Sebaran}

Analisis pada penelitian ini menggunakan uji kecocokan Smirnov-Kolmogorov. Pengujian dilakukan dengan cara membandingkan probabilitas pada tiap-tiap variabel dari suatu distribusi yang hasilnya akan didapat perbedaan $(\Delta)$. Perbedaan maksimum $\left(\Delta_{\text {maks }}\right)$ yang dihitung dibandingkan dengan perbedaan kritis $\left(\Delta_{\text {cr }}\right)$ untuk banyaknya varian tertentu. Sebaran dikatakan sesuai jika $\Delta_{\text {maks }}<\Delta_{\text {cr }}$ (Soewarno, 1995).

\section{Hujan Efektif}

Hujan efektif adalah bagian dari hujan total yang menghasilkan limpasan langsung. Hujan efektif merupakan hasil perkalian dari koefisien limpasan dengan Hujan total seperti ditunjukkan pada Persamaan 3.

$\boldsymbol{H}_{\text {eff }}=\boldsymbol{X}_{T} \times \boldsymbol{c}$

dengan:

$H_{\text {eff }} \quad$ : hujan efektif ( $\left.\mathrm{mm}\right)$,

$X_{t} \quad$ : hujan rancangan $(\mathrm{mm})$,

c : koefisien limpasan.

\section{Waktu Konsentrasi}

Waktu konsentrasi adalah waktu yang diperlukan untuk bergeraknya air dari titik aliran terjauh dari suatu DAS sampai dengan titik pelepasan. Pada penelitian ini, digunakan rumus Kirpich seperti ditampilkan pada Persamaan 4.

$t_{c}=0,06628 \cdot k \cdot L^{0,77} \cdot S^{-0,385}$

dengan:

$t_{c} \quad$ : waktu konsentrasi (jam),

k : koefisien Kirpich, dapat dilihat pada Tabel 3,

$L \quad$ : panjang saluran utama dari hulu sampai penguras $(\mathrm{km})$,

$S$ : kemiringan rata-rata saluran (m).

\section{Intensitas Hujan}

Intensitas curah hujan adalah ketinggian curah hujan yang terjadi pada suatu kurun waktu di mana air tersebut berkonsentrasi. Penelitian ini menggunakan metode Mononobe hasil modifikasi dengan rumus yang disajikan pada Persamaan 5 (Rosadana Nurir, 2015).

$I_{t}=\frac{R_{24}}{t_{c}}\left[\frac{t_{c}}{t}\right]^{2 / 3}$

dengan:

$I_{t} \quad=$ Intensitas curah hujan pada jam ke- $t(\mathrm{~mm} / \mathrm{jam})$,

$R_{24}=$ tinggi hujan rancangan dalam 24 jam $(\mathrm{mm})$,

$t_{c} \quad=$ waktu konsentrasi (jam), dan

$t \quad=$ jam ke-1 s.d. jam ke- $t c$ (jam).

\section{Hujan Jam-jaman}

Metode yang digunakan pada penelitian ini adalah Alternating Block Method (ABM). Alternating Block Method (ABM) adalah salah satu metode penentuan pola hujan jam-jaman dengan cara sederhana dengan membuat byetograph rencana dari kurva Intensitas-Durasi-Frekuensi (IDF) (Chow et al., 1988).

\section{Hidrograf Satuan Sintetis Limantara}

Pada penelitian ini, digunakan HSS Limantara. Parameter DAS yang dipakai dalam HSS Limantara ada 5 macam, yaitu Luas DAS (A), Panjang sungai utama (L), Panjang sungai diukur sampai titik, terdekat dengan titik berat 
DAS (Lc), Kemiringan sungai (s) dan Koefisien kekasaran (n). Spesifikasi Teknis HSS Limantara dapat dilihat pada Tabel 1, digunakan rumus HSS Limantara seperti ditampilkan pada Persamaan 6.

Tabel 1 Spesifikasi Teknis HSS Limantara

\begin{tabular}{lccc}
\hline \multicolumn{1}{c}{ Uraian } & Notasi & Satuan & Kisaran \\
\hline Luas DAS & $\mathrm{A}$ & $\mathrm{Km}^{2}$ & $0,325-1667,500$ \\
\hline Panjang sungai utama & $\mathrm{L}$ & $\mathrm{Km}$ & $1,16-62,48$ \\
\hline Jarak titik berat DAS ke outlet & Lc & $\mathrm{Km}$ & $0,50-29,386$ \\
\hline Kemiringan sungai utama & $\mathrm{S}$ & - & $0,00040-0,12700$ \\
\hline Koefisien kekasaran DAS & $\mathrm{N}$ & - & $0,035-0,070$ \\
\hline Bobot Luas hutan & Af & $\%$ & $0,00-100$ \\
\hline
\end{tabular}

$\mathrm{Qp}=0,042 \times \mathrm{A}^{0,451} \times \mathrm{L}^{0,497} \times \mathrm{Lc}^{-0,131} \times \mathrm{n}^{0,168}$

$\mathrm{Qn}=\mathrm{Qp} \times\left[\frac{t}{T p}\right]^{1,107}$

$\mathrm{Qn}=\mathrm{Qp} \times 10^{0,175}(T p-t)$

$\mathrm{Tp}=\operatorname{tg}+0,8 \mathrm{tr}$

dengan:

Qp = debit puncak banjir hidrograf satuan $\left(\mathrm{m}^{3} / \mathrm{dt} / \mathrm{mm}\right)$

$\mathrm{A}=$ luas DAS $\left(\mathrm{km}^{2}\right)$

$\mathrm{L} \quad=$ panjang sungai utama $(\mathrm{km})$

Lc $\quad=$ panjang sungai daro outlet sampai titik terdekat dengan titik berat DAS

$\mathrm{s} \quad=$ kemiringan sungai utama

$\mathrm{n}=$ koefisien kekasaran DAS

$0,042=$ koefisien untuk konversi $\operatorname{satuan}\left(\mathrm{m}^{0,25} / \mathrm{dt}\right)$

Qn = debit pada persamaan kurva naik $\left(\mathrm{m}^{3} / \mathrm{dt} / \mathrm{mm}\right)$

$\mathrm{t} \quad=$ waktu hidrograf (jam)

Tp = waktu naik hidrograf atau waktu mencapai puncak hidrograf (jam)

Qt $=$ debit pada persamaan kurva turun $\left(\mathrm{m}^{3} / \mathrm{dt} / \mathrm{mm}\right)$

$\operatorname{tg}=$ waktu konsentrasi hujan (jam)

\section{Analisis Banjir}

Chow dkk. (1998) menerangkan bahwa standard step method dikembangkan dari persamaan garis energi total dari aliran pada saluran terbuka.

Seperti yang sudah disebutkan sebelumnya, penelusuran banjir dengan standard step method menerapkan persamaan rumus kekekalan energi, yang ditunjukkan pada Persamaan 10 dan 11 berikut.

$H=\mathrm{z}+\mathbf{h}+\frac{V^{2}}{2 g}=\mathrm{z}+E$
$\mathrm{~S}_{\mathrm{o}}=\frac{Q^{2} n^{2}}{A n^{2} R n^{\frac{4}{3}}}$

dengan:

$\mathrm{H} \quad=$ tekanan total $(\mathrm{m})$,

$\mathrm{z} \quad=$ jarak vertikal dasar saluran diatas bidang dasar $(\mathrm{m})$,

$\mathrm{h}=$ kedalaman aliran tegak lurus bidang dasar $(\mathrm{m})$,

$\alpha \quad=$ koefisien energi,

$\mathrm{V} \quad=$ kecepatan aliran $\left(\mathrm{m}^{2} / \mathrm{dt}\right)$,

A $=$ luas penampang $\left(\mathrm{m}^{2}\right)$,

$\mathrm{R}=$ Jari-jari hidrolik (m),

Q = debit aliran sungai $\left(\mathrm{m}^{3} / \mathrm{dt}\right)$,

$\mathrm{n}=$ koefisien Manning,

$S_{0} \quad=$ kemirirngan dasar sungai. 


\section{Pembuatan Peta Potensi Wilayah Tergenang dengan Sistem Informasi Geografis}

Sistem informasi geografis adalah teknologi informasi yang dapat menganalisis, menyimpan, dan menampilkan data spasial dan non-spasial, SIG mengkombinasikan perangkat lunak berbasis data relasional dan paket perangkat lunak Computer Aided Design (CAD) (Guo Bo et. all 2000 dalam Prahasta, 2009).

\section{METODE PENELITIAN}

Metode penelitian yang digunakan pada penelitian ini adalah deskriptif kuantitatif. Dimana untuk mendapatkan hubungan antara waktu dan salah satu unsur aliran menggunakan metode HSS Limantara. Sedangkan untuk metode analisis banjir menggunakan Standard Step Method. dengan memanfaatkan beberapa data sekunder yang meliputi:

1. Peta digital dengan skala 1:25 000 Kota Surakarta produksi Badan Informasi Geospasial (dahulu Bakosurtanal), termasuk di dalamnya peta administrasi, peta sungai, dan peta kontur.

2. Peta Digital Elevation Method (DEM) produksi United States Geological Survey (USGS)

3. Data curah hujan dari 3 (dua) stasiun terdekat dari wilayah tinjauan; yakni Stasiun Pabelan di bawah Balai Besar Wilayah Sungai (BBWS) Bengawan Solo serta Baki dan Mojolaban di bawah Balai Pekerjaan Umum Sumber Daya Air dan Penataan Ruang (BPUSDATARU) Bengawan Solo dari tahun 1997 sampai 2017.

Data di atas kemudian diolah dengan menggunakan bebrapa perangkat digital yang terdiri dari:

1. Microsoft Excel untuk perhitungan analisis data hujan.

2. ArcGIS versi 10.2 untuk mengolah peta digital serta properti terkait pemetaan banjir.

\section{HASIL DAN PEMBAHASAN}

\section{Penelusuran Banjir dengan Standard Step Method}

Tabel 2 menampilkan rekapitulasi hasil analisis banjir Permodelan I untuk masing-masing debit maksimum akibat hujan kala ulang dan akibat hujan 3-harian dengan batasan yang digunakan adalah pintu Plalan tertutup, sehingga tinggi air dipintu menggunakan ketinggian maksimum air saat dimana pintu harus ditutup, yaitu 2,5 $\mathrm{m}$ (DPU, 2003). Dan Tabel 3 menampilkan rekapitulasi hasil analisis banjir Permodelan II untuk masing-masing debit maksimum akibat hujan kala ulang dan akibat hujan 3-harian dengan asumsi pintu dibuka, sehingga ketinggian awal analisis menggunakan tinggi dari Sungai Premulung pada titik pertemuan.

Tabel 2 Rekapitulasi Analisis Banjir pada Keadaan Debit Maksimum Permodelan I

\begin{tabular}{ccccccc}
\hline \multirow{2}{*}{$\mathrm{X}$} & \multicolumn{5}{c}{ Kejadian T Maksimum (dalam m $\mathrm{m}^{3} /$ detik, jam ke-3) } \\
\cline { 2 - 7 } & $\mathrm{H}_{2}$ & $\mathrm{H}_{5}$ & $\mathrm{H}_{20}$ & $\mathrm{H}_{25}$ & $\mathrm{H}_{50}$ & $\mathrm{H}_{3 \text { Harian }}$ \\
\hline 0 & 2,5811 & 2,5912 & 2,6053 & 2,6076 & 2,6147 & 2,8004 \\
\hline 100 & 2,4180 & 2,4195 & 2,4216 & 2,4220 & 2,4230 & 2,4508 \\
\hline 200 & 2,3387 & 2,3421 & 2,3467 & 2,3475 & 2,3499 & 2,4116 \\
\hline 300 & 2,2481 & 2,2519 & 2,2572 & 2,2580 & 2,2607 & 2,3304 \\
\hline 400 & 2,1579 & 2,1622 & 2,1682 & 2,1692 & 2,1722 & 2,2509 \\
\hline 500 & 2,0683 & 2,0731 & 2,0799 & 2,0810 & 2,0844 & 2,1734 \\
\hline 600 & 1,9791 & 1,9846 & 1,9922 & 1,9935 & 1,9973 & 2,0977 \\
\hline 700 & 1,8904 & 1,8966 & 1,9052 & 1,9066 & 1,9109 & 2,0237 \\
\hline 800 & 1,8020 & 1,8089 & 1,8185 & 1,8200 & 1,8249 & 1,9507 \\
\hline 900 & 1,7135 & 1,7210 & 1,7315 & 1,7332 & 1,7386 & 1,8772 \\
\hline 1000 & 1,6239 & 1,6320 & 1,6433 & 1,6451 & 1,6509 & 1,7998 \\
\hline 1100 & 1,5316 & 1,5399 & 1,5515 & 1,5534 & 1,5593 & 1,7124 \\
\hline 1200 & 1,4332 & 1,4411 & 1,4519 & 1,4537 & 1,4592 & 1,6027 \\
\hline 1300 & 1,3224 & 1,3281 & 1,3361 & 1,3374 & 1,3414 & 1,4465 \\
\hline 1400 & 1,1861 & 1,1865 & 1,1872 & 1,1873 & 1,1876 & 1,1962 \\
\hline 1500 & 0,9983 & 0,9870 & 0,9714 & 0,9688 & 0,9609 & 0,7548 \\
\hline 1600 & 0,7038 & 0,6674 & 0,6171 & 0,6089 & 0,5833 & 0,5485 \\
\hline
\end{tabular}


Tabel 3 Rekapitulasi Analisis Banjir pada Keadaan Debit Maksimum Permodelan II Kejadian T Maksimum (dalam $\mathrm{m}^{3} /$ detik, jam $\mathrm{X}$

\begin{tabular}{ccccc} 
& $\mathrm{H}_{5}$ & $\mathrm{H}_{10}$ & $\mathrm{H}_{25}$ & $\mathrm{H}_{50}$ \\
\hline 0 & 5,1040 & 5,5817 & 8,0244 & 8,2344 \\
\hline 100 & 4,8496 & 5,3007 & 7,6037 & 7,8014 \\
\hline 200 & 4,6053 & 5,0278 & 7,1856 & 7,3709 \\
\hline 300 & 4,3605 & 4,7546 & 6,7675 & 6,9405 \\
\hline 400 & 4,1161 & 4,4818 & 6,3497 & 6,5103 \\
\hline 500 & 3,8722 & 4,2095 & 5,9322 & 6,0804 \\
\hline 600 & 3,6292 & 3,9380 & 5,5151 & 5,6510 \\
\hline 700 & 3,3871 & 3,6674 & 5,0986 & 5,2222 \\
\hline 800 & 3,1465 & 3,3983 & 4,6831 & 4,7944 \\
\hline 900 & 2,9077 & 3,1311 & 4,2689 & 4,3680 \\
\hline 1000 & 2,6716 & 2,8666 & 3,8570 & 3,9438 \\
\hline 1100 & 2,4391 & 2,6061 & 3,4485 & 3,5233 \\
\hline 1200 & 2,2115 & 2,3513 & 3,0458 & 3,1088 \\
\hline 1300 & 1,9896 & 2,1039 & 2,6528 & 2,7045 \\
\hline 1400 & 1,7722 & 1,8646 & 2,2764 & 2,3181 \\
\hline 1500 & 1,5463 & 1,6242 & 1,9254 & 1,9602 \\
\hline 1600 & 1,2465 & 1,3201 & 1,5821 & 1,6159 \\
\hline
\end{tabular}

\section{Pemetaan Wilayah Potensi Tergenang}

Pemetaan wilayah yang berpotensi tergenang dilakukan dengan menggunakan program ArcMap 10.2.1, yang hasilnya dapat dilihat pada Gambar 1 hingga Gambar 4.

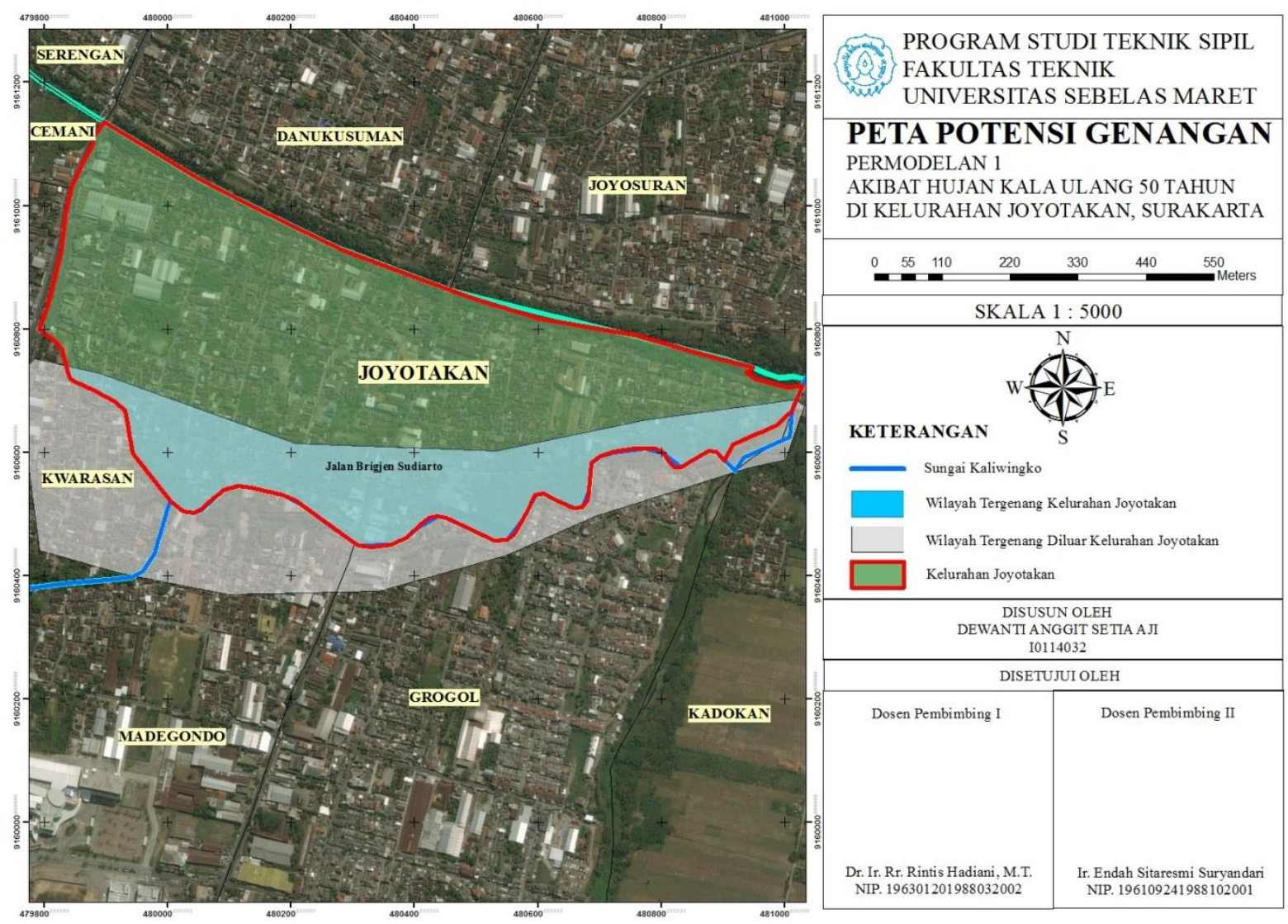

Gambar 1 Peta Potensi Genangan Permodelan I akibat Hujan Kala Ulang 50 Tahun 


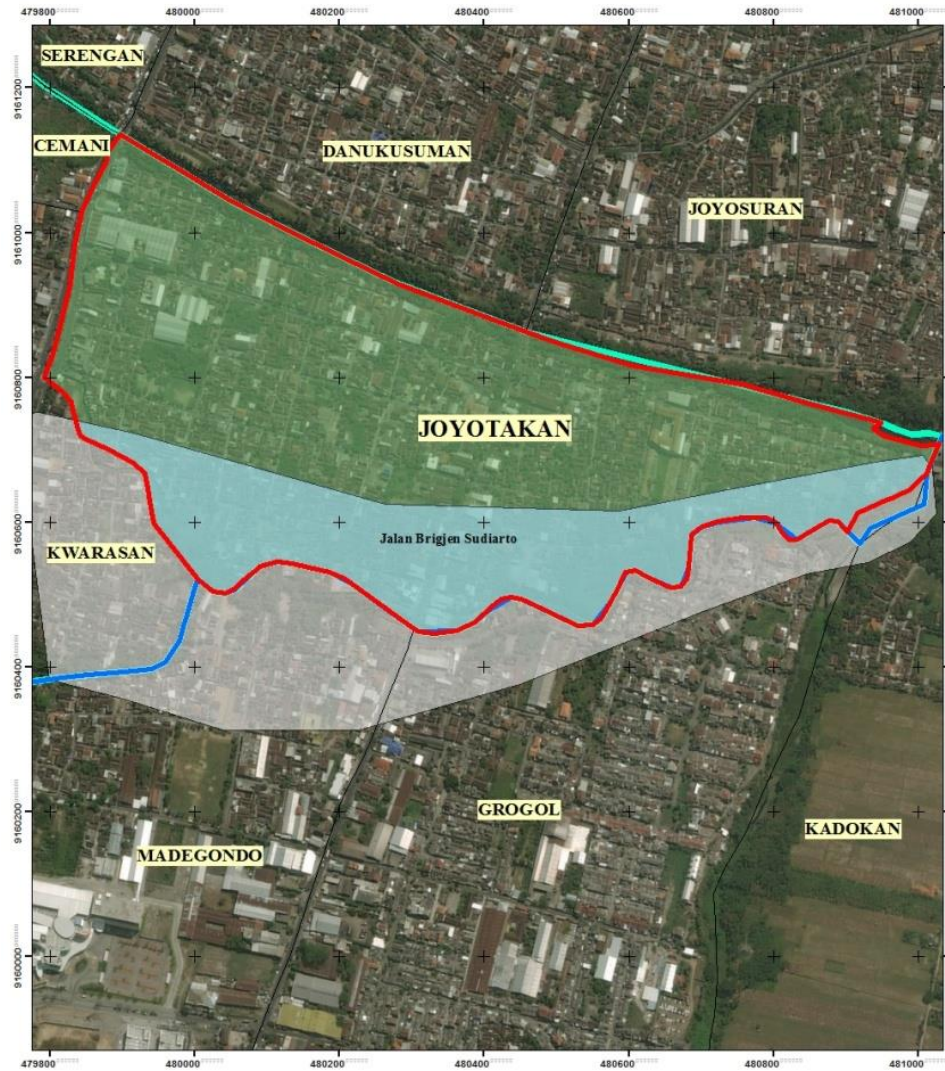

PROGRAM STUDI TEKNIK SIPIL
FAKULTAS TEKNIK
UNIVERSITAS SEBELAS MARET

PETA POTENSI GENANGAN

PERMODELAN 1

AKIBAT HUJAN KALA ULANG 3 HARIAN

DI KELURAHAN JOYOTAKAN, SURAKARTA

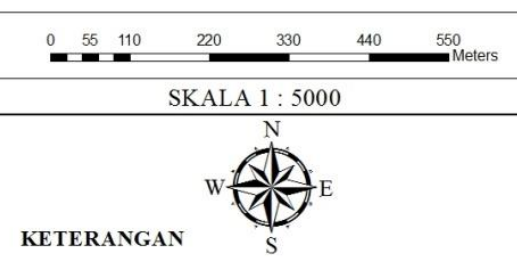

KETERANGAN

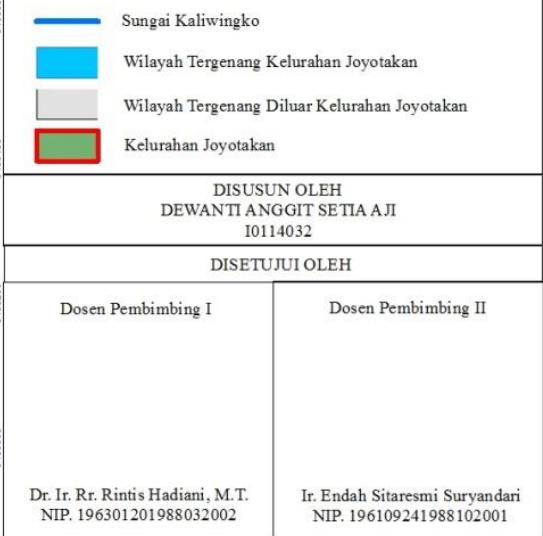

Gambar 2 Peta Potensi Genangan Permodelan I akibat Hujan 3-harian Maksimum

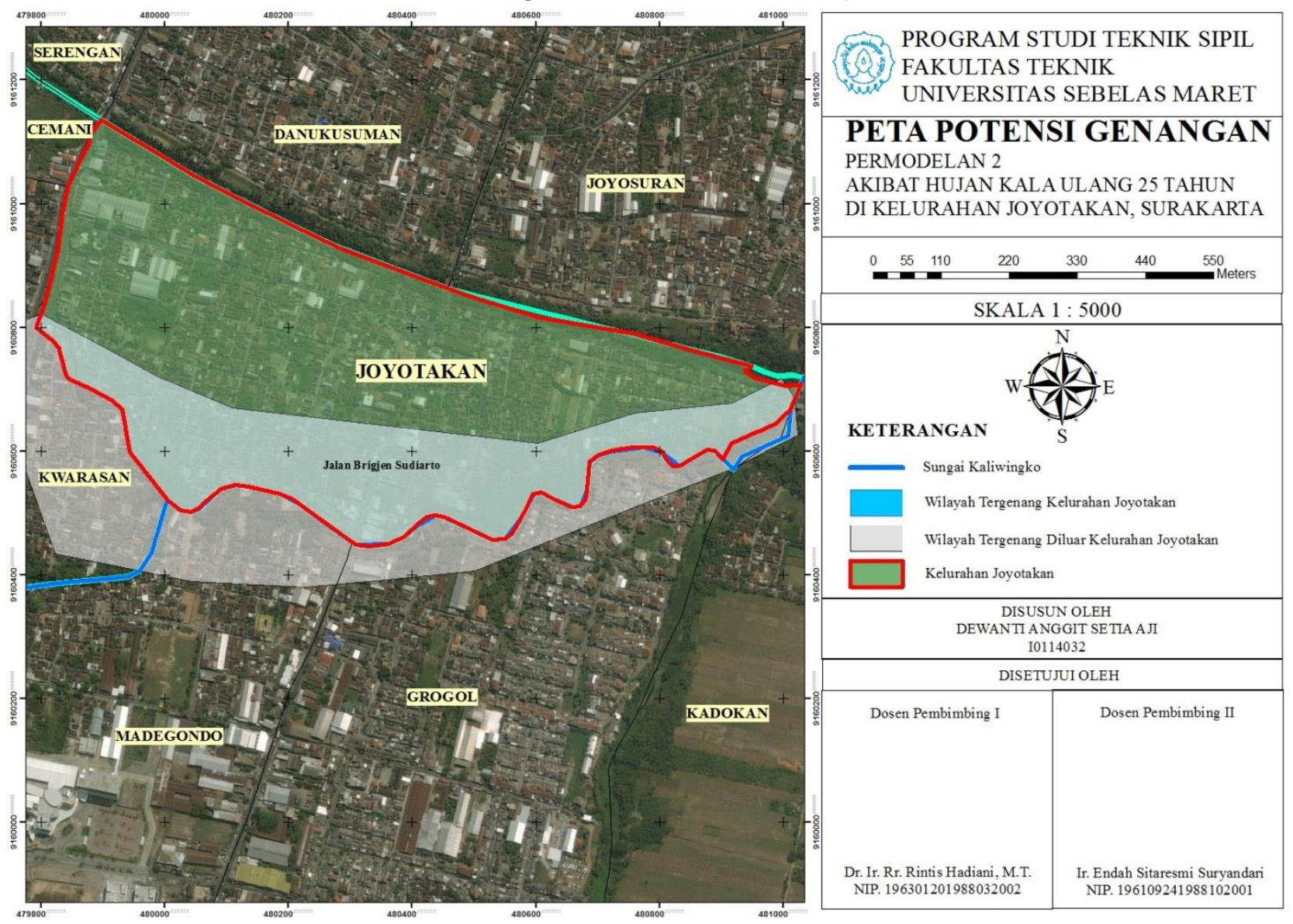

Gambar 3 Peta Potensi Genangan Permodelan II akibat Hujan Kala Ulang 25 Tahun 


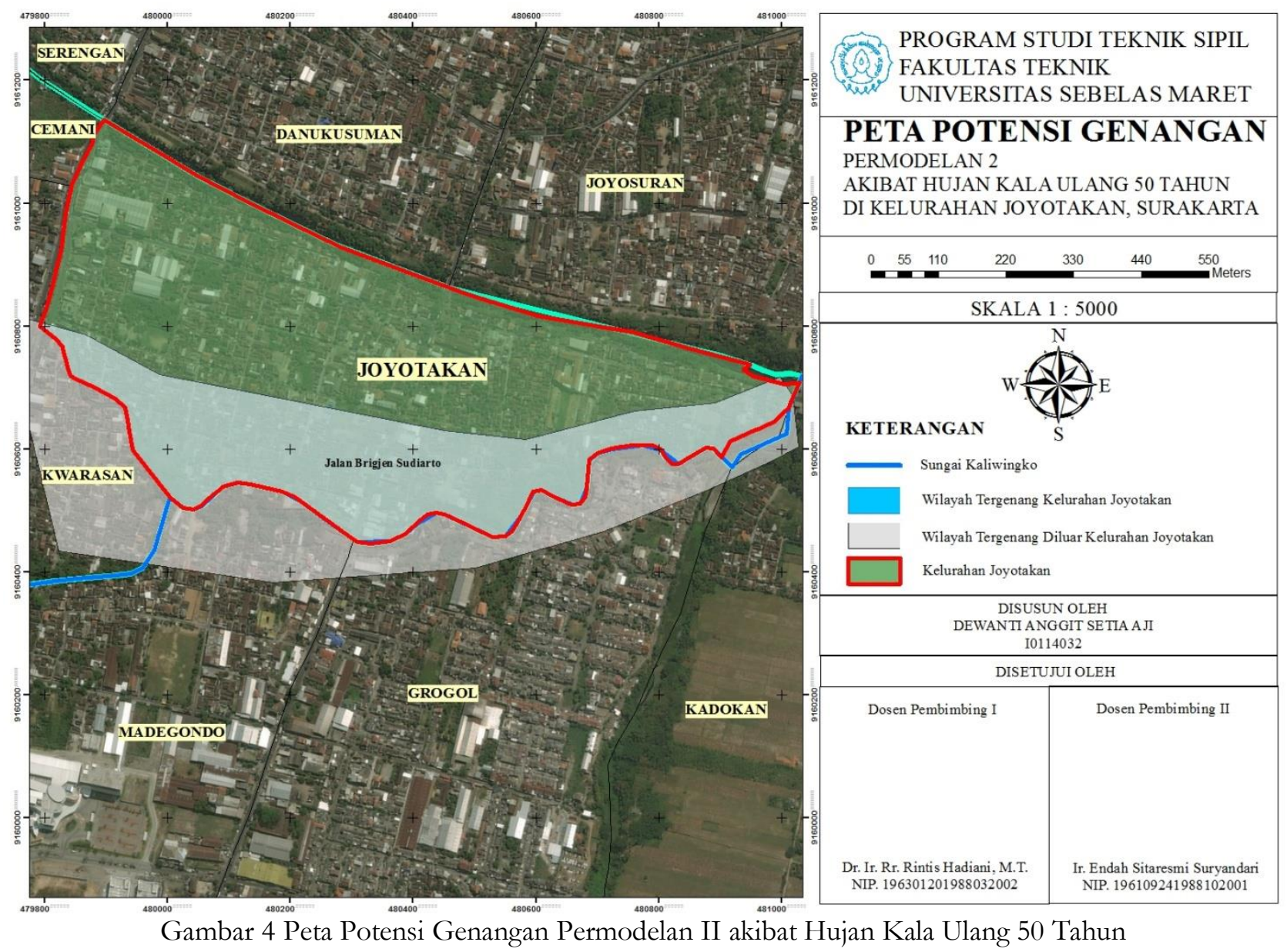

\section{SIMPULAN}

Berdasarkan penelitian yang telah dilakukan, dapat disimpulkan bahwa:

1. Nilai debit banjir periode ulang hidrograf satuan sintetis Limantara di Kelurahan Joyotakan pada kala ulang $\mathrm{Q}_{2}=32,4281 \mathrm{~m} 3 /$ detik, $\mathrm{Q}_{5}=34,4001 \mathrm{~m} 3 /$ detik, $\mathrm{Q}_{10}=35,7058 \mathrm{~m} 3 /$ detik. $\mathrm{Q}_{20}=36,9583 \mathrm{~m} 3 /$ detik, $\mathrm{Q}_{25}$ $=37,3555 \mathrm{~m}^{3} /$ detik, $\mathrm{Q}_{50}=38,5794 \mathrm{~m} 3 /$ detik dan $\mathrm{Q}_{3 \text { Harian }}=62,4224 \mathrm{~m} 3 /$ detik.

2. Elevasi muka air banjir berdasarkan analisis banjir dengan Standard Step Method pada Permodelan I adalah $\mathrm{Q}_{2}$ $=2,66415 \mathrm{~m}, \mathrm{Q}_{5}=2,6592 \mathrm{~m}, \mathrm{Q}_{10}=2,6715 \mathrm{~m}, \mathrm{Q}_{20}=2,6838 \mathrm{~m}, \mathrm{Q}_{25}=2,6878 \mathrm{~m}, \mathrm{Q}_{50}=2,7003 \mathrm{~m}$ dan $\mathrm{Q}_{3}$ Harian $=3,0243 \mathrm{~m}$. Elevasi muka air banjir pada Permodelan II adalah $\mathrm{Q}_{5}=5,2492 \mathrm{~m}, \mathrm{Q}_{10}=5,7415 \mathrm{~m}, \mathrm{Q}_{25}$ $=8,2078 \mathrm{~m}$ dan $\mathrm{Q}_{50}=8,4303 \mathrm{~m}$.

3. Pemetaan daerah genangan banjir kelurahan Joyotakan secara digital menggunakan software ArcGIS dapat dilihat pada Gambar 4.15 sampai 4.25, dengan Permodelan I pintu air tertutup sehingga ketinggian di Kaliwingko adalah 2,5 m, pompa dalam keadaan tidak aktif. Permodelan II pintu air terbuka, ketinggian air di titik pintu air Plalan mengikuti ketinggian air di Sungai Premulung, pompa dalam keadaan aktif.

\section{REKOMENDASI}

Terdapat beberapa hal yang diharapkan dapat diperbaiki, agar menjadi perbaikan dalam proses maupun penelitian, yaitu:

1. Sebelum memfinalisasi metode yang digunakan, sebaiknya diverifikasi terlebih dahulu ketersediaan data yang digunakan, agar mempercepat saat melakukan pengolahan data.

2. Diperlukan adanya penelitian lanjut mengenai banjir daerah Joyotakan, dengan menganalisis pengaruh dari runoff Joyotakan bagian Barat dan pompa air yang berada pada Joyotakan bagian Timur.

\section{UCAPAN TERIMA KASIH}

Ucapan terima kasih pertama ditujukan kepada Allah SWT atas limpahan rahmat dan nikmatnya. Selanjutnya kepada orangtua yang telah memberikan dukungan moril dan materi. Tak lupa kepada Dr. Ir. Rr. Rintis Hadiani, 
M.T. dan Ir. Endah Sitaresmi Suryandari selaku dosen pembimbing yang telah memberi arahan dan masukan dalam penelitian ini. Serta teman-teman yang menjadi bagian dalam hidup Anggit.

\section{REFERENSI}

Andromeda, Virdya Nurlaily. 2016. Penelusuran Banjir dengan Metode Kinematik di Daerah Aliran Sungai Temon, Wonogiri. Matriks Teknik Sipil. Surakarta.

Azhari, Dony dkk. 2017. Kajian Debit Rancangan Banjir dan Kapasitas Penampang Sungai Baki. Skripsi. UNS

Bagas Hendi Pratama. 2018. Analisis Banjir Tahunan Kota Surakarta Menggunakan Watershed Modelling System (WMS). Skripsi. UNS

Bambang, T. 1995. Hidraulika II. Yogyakarta: Beta Offset

Bambang, T. 2009. Hidrologi Terapan. Yogyakarta: Beta Offset

Chow, V.T., Maidment, D.R., and Mays, L.W. 1988. Applied Hydrology. McGraw-Hill. Singapore.

Dewandaru, Gemma Galgani Tunjung dan Umboro Lasmito. 2014. Studi Penanggulangan Banjir Kali Lamong Terhadap Genangan di Kabupaten Gresik. Jurnal Teknik POMITS. Volume 3, No. 2, (2014) ISSN:2337-3539

Dinas Pekerjaan Umum. 2003. Laporan Akhir Sementaa Perencanaan/DED Penanggulangan Banjir Kali Wingko Kota Surakarta. Surakarta.

Fauziyyah, Amiroh Lina. 2014. Backwaterpada Sungai Dengkeng Berdasarkan Metode Tahapan Standar. Skripsi. UNS

Hamdani, Hendi. dkk. 2014. Analisa Daerah Rawan Banjir Menggunakan Aplikasi Sistem Informasi Geografis (Studi Kasus Pulau Bangka). Jurnal Konstruksi. ISSN: 2302-7312 Vol. 12 No. 1.

Idfi, Gilang. 2017. Perbandingan Model Aliran Banjir Unsteady Flow dan Steady Flow pada Sungai Ngotok Ring Kanal. Jurnal Bangunan. Vol. 22, No.2, Oktober 2017: 31-40.

Ikhsan, Cahyono dkk. 2017. Analisis Backwater di Sekitar Pertemuan Kali Anyar Surakarta dengan Sungai Bengawan Surakarta. Skripsi. UNS.

Jadmiko, Sigit., Rintis Hadiani, dan Agus Prijadi Saido. 2013. Banjir Tabunan Sub Daerah Aliran Sungai Bengawan Surakarta Hulu 3 dengan Sistem Informasi Geografis. Fakultas Teknik. Universitas Sebelas Maret. Surakarta.

Kurniawan, dkk. 2017. Mengisi Data Hujan yang Hilang dengan Metode Autoregressive dan Metode Reciprocal dengan Pengujian Debit Kala Ulang (Studi Kasus di D AS Bakalan). E-Jurnal Matriks Teknik Sipil, 13, 15-23.

Limantara, Montarcih. 2010. Hidrologi Praktis. CV. Lubuk Agung. Bandung.

Miller, Jeffrey E. 1984. Basic Concepts of Kinematic-Wave Models. U.S. Geological Survey Professional Paper 1302.

Montarcih, Lily. 2010. Penelusuran Banjir lewat Sungai : Studi kasus Sungai Dodokan. CV Citra Malang. Malang.

Natakusumah, Dantje K dkk. 2011. Prosedur Perbitungan Hidrograf Satuan Sintesis dengan Cara ITB dan Beberapa Contoh Penerapannya. Final Report. ITB.

Naulita, Maria Anisa., Sobriyah, dan Siti Qomariyah. 2015. Metode Penelusuran Banjir pada Sungai Dengkeng dengan Metode Gabungan O'Donnel dan Muskingum-Cunge dan Metode Muskingum Extended. Fakultas Teknik. Universitas Sebelas Maret. Surakarta.

Nurir, Rosadana. 2016. Transformasi Hujan Harian ke Hujan Jam-jaman Menggunkaan Metode Mononobe dan Pengalibragaman Hujan Aliran (Studi Kasus di DAS Tirtomoyo). Matriks Teknik Sipil. Surakarta.

Ponce, V.M. 1989. Engineering Hydrology. Prentice Hall. New Jersey.

Robot, Jeffier Andrew, dkk. 2014. Analisis Debit Bnajir Sungai Ranoyapo Menggunakan Metode HSS Gama-1 dan HSS Limantara. Jurnal Sipil Statik Vol.2 No.1. Manado.

Sigit Jadmiko, RR. Rintis Hadiani dan Agus P.Saido. 2013. Banjir tahunan Sub Daerah Aliran Sungai Bengawan Surakarta Hulu 3 dengan Sistem Informasi Geografis. Skripsi. UNS.

Sobriyah. 2012. Model Hidrologi. Sebelas Maret University Press. Surakarta.

Sobriyah dan Sudjarwadi. 2000. Penggabungan Metode O'Donnell dan Muskingum-Cunge untuk Penelusuran Banjir pada Jaringan Sungai. Media Teknik No. 4 Tahun XXII Edisi November 2000. ISSN 0216-3012.

Soewarno. 1995. Hidrologi: Aplikasi Metode Statistik untuk. Analisa Data Jilid 1. Penerbit Nova. Bandung.

Sri Harto, 1993. Analisis Hidrologi, Gramedia Pustaka Utama, Jakarta.

Suripin. 2004. Sistem Drainase Perkotaan yang Berkelanjutan. Andi Offset.Yogyakarta.

Waskito, Sigit Nur. 2016. Analisis Banjir 2 Harian Maksimum Tabunan dengan ARCGIS di DAS Temon. Matriks Teknik Sipil. Surakarta. 